\title{
Characterisation of fatigue crack tip field in the presence of significant plasticity
}

\author{
B. Lin, S. Alshammrei, T. Wigger, J. Tong ${ }^{*}$ \\ Mechanical Behaviour of Materials Laboratory, School of Mechanical and Design Engineering, \\ University of Portsmouth, PO1 3DJ, UK
}

\begin{abstract}
Characterisation of a fatigue crack tip in the presence of significant plasticity has been challenging due to the lack of suitable tools and lack of knowledge of material constitutive information under cyclic loading. In this paper, Digital Image Correlation (DIC) and integrated finite element (FE) analyses have been used to characterise the crack-tip field beyond the small-scale yielding (SSY) regime in a stainless steel $316 \mathrm{~L}$ of a compact-tension (CT) specimen under mode I loading conditions. The non-linear characteristics of the near-tip deformation field were verified by the poor fit to the William's regression and the overestimation of the stress intensity factor $\mathrm{K}$. The extent of the crack tip plasticity was estimated using a detailed constitutive material model and compared with the estimated by Irwin. The displacement fields local to a stationary fatigue crack were mapped using DIC, and inputted into the FE model as boundary conditions so that an integrated FE analysis was carried out. Fatigue pre-cracking was simulated in the FE analysis prior to the full-field analysis of the fatigue crack tip, including stress/strain distributions ahead of the crack tip and the crack opening displacement (COD) under selected loading conditions. Although a distinct "knee" was captured from the compliance curves in both the DIC measurements and the FE analyses, consistent with the existing knowledge on the phenomenon of crack closure, it does not appear to correlate with the crack driving force measured by the J-integral.
\end{abstract}

\section{Introduction}

Quantitative characterisation of the deformation field around a fatigue crack tip is challenging in the presence of significant plastic deformation. A continuum mechanics framework of crack tip deformation and extension by fatigue was given by Rice [1], where elastic-plastic stress analysis was presented by extending the elastic treatments and the plastic deformation estimated for idealised geometries. A number of models were proposed for approximate treatments of crack tip plasticity based on slip or tensile yielding on discrete surfaces emanating from the crack tip, notably from [2-4];

\footnotetext{
*Corresponding author: jie.tong@port.ac.uk
} 
or slip line theory [5]. The difficulties in experimental validation and the prevalence of small scale yielding (SSY) conditions in engineering applications have led to the predominance of linear elastic fracture mechanics approaches to crack tip characterisation, typically by the stress intensity factor $\mathrm{K}$, proposed by Paris et al [6] and rationalised by Rice [7], for the correlation of fatigue crack growth rate. It has since been broadly accepted that the use of an elastic stress intensity factor range, $\mathrm{K}$, is adequate in most engineering applications under SSY conditions, although the role of load ratio $\mathrm{R}$ was also recognised and subsequently rationalised through the consideration of a concept of "crack closure", a phenomenon first reported by Elber [8], who observed that a crack may be partially closed when subjected to cyclic tensile loads. A general feature of crack closure is a change of stiffness in the load against displacement curves, marked by a "knee" in the measured compliance curves during loading and unloading, which is considered to be indicative of "crack opening", from which Kop may be estimated and an "effective" stress intensity factor $K_{\text {eff }}\left(K_{\max }-K_{o p}\right)$ may be obtained. Of the main types of crack closure, plasticity-induced crack closure has been used as the default interpretation of load ratio effects, and is incorporated in some fatigue life prediction models. This mechanism, if at work, should be most relevant in the presence of large plasticity.

A number of methods have been employed to measure the crack closure level, notably by compliance method using potential drop and displacement gauges [9], and more recently, by digital image correlation (DIC) [11-14]. The impact of crack closure measured from compliance curves on the strain ahead of the crack tip and overall stress intensity factor was examined for the first time by Tong et al [14], where full-field measurements were made using DIC to obtain COD at selected distance behind the crack tip, the normal strains ahead of the crack tip and the stress intensity factor fitted from the displacement fields. The results show that the crack closure has little impact on the normal strains ahead of the crack tip or the crack-driving force $\mathrm{K}$.

The present work is an extension of our earlier work on full-field characterisation of fatigue crack tip in a stainless steel $316 \mathrm{~L}$, considering large deformation beyond SSY regime. The primary objective of the work is to utilise the DIC measurement technique combined with the FE analysis to investigate the effects of crack tip plasticity on the crack opening and the crack driving force. The DIC technique was used to map the crack tip deformation fields under selected load cases, and the extent of crack tip plasticity was evaluated using a detailed material constitutive model. The displacement fields were mapped using William's series expansion and the overestimation of $\mathrm{K}$ was revealed. The CODs behind the crack tip were measured at selected locations using both DIC and FE, and the crack driving force J was estimated, from which the elastic and the plastic components were 
separated. An attempt was also made to correlate the CODs and the crack driving force J with little success.

\section{Experimental procedures}

\subsection{Material and specimen geometry}

The material used for this experiment is stainless steel $316 \mathrm{~L}$, where the yield strength is $280 \mathrm{MPa}$, the modulus of elasticity is $193 \mathrm{GPa}$ and Poisson `s ratio of 0.3. An average grain size of the material was measured to be approximately $17 \mu \mathrm{m}$. A compact tension specimen (CT) was employed with thickness of $7 \mathrm{~mm}$, width of $60 \mathrm{~mm}$, and notch size of $12 \mathrm{~mm}$. Further experimental details are given elsewhere [14].

\subsection{Mechanical testing}

Instron servo-hydraulic machine with a loading cell of $25 \mathrm{kN}$ was utilised for mechanical testing. Precracking was carried out using a load shedding scheme where the maximum load was reduced step by step from $\triangle \mathrm{P}=11 \mathrm{kN}$ to $4.9 \mathrm{kN}$, corresponding to $\Delta \mathrm{K}=25 \mathrm{MPaVm}$ to $15 \mathrm{MPaVm}$. Loading frequency and load ratio were $10 \mathrm{~Hz}$ and 0.1 , respectively. Crack length was monitored using surface replicas technique and CCD camera until a suitable fatigue crack length was obtained at about $a / W=0.32$, where the final pre-cracking stage was concluded at $\Delta K \approx 15 \mathrm{MPaVm}$ and a total crack growth of $7.30 \mathrm{~mm}$. Fatigue testing was then conducted under cyclic loading at three levels of stress intensity factors, $\Delta K=15,20$, and $25 \mathrm{MPaVm}$. Twenty cycles were allowed to elapse at each load case prior to the DIC measurements taken incrementally during a full load cycle. The load was increased monotonically from $\mathrm{P}_{\min }$ to $\mathrm{P}_{\max }$ at a fixed increment of $10 \% \mathrm{P}_{\max }$, and was held at each loading step for $10 \mathrm{sec}$ to allow image acquisition; a procedure repeated for unloading. A total of 21 images was recorded during loading and unloading for each cycle.

\subsection{Digital Image correlation}

Digital image correlation (DIC) was carried out using Lavision system (LAVISION, GMBH) which consisted of a CCD camera ( $2456 \times 2058$ pixels) and a Schneider Kreuznach F2.8 50-mm lens with 100-mm extension tubes (Fig. 1). A field of view (FOV) was taken as $1.2 \mathrm{~mm} \times 1.1 \mathrm{~mm}$, resulting in a spatial resolution of $0.54 \mu \mathrm{m} /$ pixel. In order to obtain suitable random patterns for the DIC correlation algorithm, the specimen surface was etched so that the microstructure of the material was exposed to allow tracking of the changes between the deformed and the un-deformed reference images. Etching solution was 50\% distilled water, 33\% chlorhydric acid and 17\% nitric acid for 2 min immersion time (E407 ASTM, disolution 88). The maximum plastic zone size was estimated to be 
approximately $1.3 \mathrm{~mm}$ at $\Delta \mathrm{K}=25 \mathrm{MPaVm}$. DIC uncertainties were assessed before the testing using five images taken at zero load, and the average standard deviations for the displacements and the strains were found to be $0.03 \mu \mathrm{m}$ and $0.15 \%$, respectively.

After recording each completed cycle, a subset size of $59 \times 59$ pixels $^{2}\left(\approx 30 \times 30 \mu \mathrm{m}^{2}\right)$ and step size of 14 pixels $(\approx 7 \mu \mathrm{m})$ were used to track surface deformations using DaVis (LaVision, version 8.4) software. By comparing the initial reference image to the deformed images under loads, the displacement maps were produced from which strain maps were obtained. Due to significant rigid body motions between the unloaded reference image and the images in loaded state, the size of the correlated area $(900 \times 900 \mu \mathrm{m} 2)$ taken is significantly smaller than that of FOV. The crack length inside of this correlated area was about one third of its width, as between $25 \%$ and $50 \%$ was recommended [15].

\subsection{Crack Opening Displacement}

Crack opening displacement (COD) was calculated from the displacement maps generated by DIC. An area of interest (AOI) of $28 \times 28 \mu \mathrm{m}^{2}$ was created at four selected positions on the crack flanks to evaluate the CODs. These positions were taken as multiples of the average grain size $\Delta=17 \mu \mathrm{m}: 1 \Delta$, $2 \Delta, 20 \Delta$ and $29 \Delta(17,34,340,500 \mu \mathrm{m})$ behind the crack tip on the $x$-axis at a fixed distance of $30 \mu \mathrm{m}$ in the $y$-direction from the crack plane. The average vertical displacements at these positions were obtained from each $\mathrm{AOI}$, and the CODs were obtained by subtracting the displacements on upper flank from the those of lower flank, as illustrated in Fig. 2. CODs were calculated for the three load cases as represented by the three stress intensity factors and plots of COD vs $\mathrm{P} / \mathrm{P}_{\max }$ were produced.

\section{Finite element analysis}

\subsection{The material model}

A nonlinear combined isotropic-kinematic hardening rule [16] was used in the material model with both isotropic and kinematic hardening considered.

The von-Mises yield criterion is expressed as:

$$
f(\sigma-\alpha)=\sqrt{\frac{3}{2}\left(S-\alpha^{d e v}\right):\left(S-\alpha^{d e v}\right)}
$$

where $\mathrm{S}$ is the deviatoric stress tensor and $\alpha^{d e v}$ is the deviatoric part of the back stress.

The yield surface size, $\sigma_{0}\left(\theta, f_{i}, \bar{\varepsilon}^{p l}\right)$, is expressed as a function of temperature $\theta$, field variables $f_{i}$ and equivalent plastic strain $\bar{\varepsilon}^{p l}$. The isotropic hardening was described by using an exponential law as: 


$$
\sigma^{0}=\sigma_{0}+Q_{\infty}\left(1-e^{-b \bar{\varepsilon}^{p l}}\right)
$$

where $\sigma_{0}\left(\theta, f_{i}\right)$ is the yield surface size when plastic strain is zero, and $Q_{\infty}\left(\theta, f_{i}\right)$ and $b\left(\theta, f_{i}\right)$ are material parameters which are calibrated by cyclic experimental data.

The equivalent plastic strain is expressed as:

$$
\bar{\varepsilon}^{p l}=\frac{1}{1-v} \sqrt{\frac{1}{2}\left[\left(\varepsilon_{1}-\varepsilon_{2}\right)^{2}+\left(\varepsilon_{2}-\varepsilon_{3}\right)^{2}-\left(\varepsilon_{3}-\varepsilon_{1}\right)^{2}\right]}
$$

The overall back stress is composed of multiple back stress components, where the evolution of the back stress components of the model is expressed as:

$$
\dot{\alpha}_{k}=C_{k} \dot{\bar{\varepsilon}}^{p l} \frac{1}{\sigma^{0}}(\sigma-\alpha)-\gamma_{k} \alpha_{k} \dot{\bar{\varepsilon}}^{p l}+\frac{1}{C_{k}} \alpha_{k} \dot{C}_{k}
$$

and the overall back stress is computed from the relation

$$
\alpha=\sum_{k=1}^{N} \alpha_{k}
$$

where $\mathrm{N}$ is the number of back stress, $C_{k}$ and $\gamma_{k}$ are kinematic hardening parameters, and $\dot{C}_{k}$ is the rate of change of $C_{k}$ with respect to temperature and field variables. In the present case only $\mathrm{k}=1$ was considered for simplicity.

Five parameters, including kinematic hardening parameters $C$ and $\gamma$, initial yield stress $\sigma_{0}$ and isotropic hardening parameters $Q_{\infty}$ and $b$, are required in the constitutive model, they are extracted from the experimental results of van Eeten and Nilsson [17]. The five material parameters as well as Young's modulus $E$ and Poisson's ratio $v$ are presented in Table 1.

\subsection{Finite element model}

A FE model was created for the same geometry of the CT specimen used in the DIC measurement, as described in Section 2. The commercial software ABAQUS [18] was used to carry out the FE analysis. To prevent hourglass mode and shear locking during the FE analysis, a 4-noded plane strain bilinear element-CPE4 with enhanced hourglass control and reduced integration in ABAQUS was applied to mesh the model. A FE model mesh is given in Fig. 3. Refined meshes were applied to the near tip region, so that the large strain gradients near the crack tip may be captured more accurately. The mesh size in the FOV (2.3) was chosen in such a way that the nodal spacing of the FE mesh matches the DIC grid size of $7.74 \mu m$, hence the two grids between the DIC and the FE model are consistently registered. This is necessary to allow the displacements from DIC to be used as the boundary conditions in the FE model to reduce the potential errors due to the interpolation of the DIC displacement fields. A mesh convergence analysis was conducted and the mesh size of $7.74 \mu \mathrm{m}$ was 
found to be adequate in capturing the crack-tip deformation. Barhli et al. [19] studied the effects of DIC image noise on the J-integral and found that the path-independency of the J-integral was lost due to the noise. To overcome this problem and obtain a path-independent J-integral, they suggested to exclude the DIC data near the crack flanks to block the noise due to poor correlation. In the present study, a region free of DIC data $(0.65 \mathrm{~mm} \times 0.1 \mathrm{~mm})$ around the crack was built in the FE model, as shown in Fig. 3b.

Contact pairs were defined between the crack surfaces to prevent potential crack penetration due to crack closure under load. No slip was assumed between the CT specimen and the loading pin, and the load was applied to the centre of the loading pin. To model residual plastic strain in the CT specimen due to pre-cracking, a sequential crack tip node-releasing technique was used to model the fatigue pre-cracking growth under cyclic loadings, where nodes are released incrementally and usually set to the size of the crack tip element [20]. Nodes may be released at the maximum loading [21], the minimum loading [22] or along the forward loading excursion [23]. To avoid a sudden change of the measured displacement [20], crack growth was simulated by releasing one node at the minimum stress for every two cycles. The final length that the crack is grown during precracking is $7.30 \mathrm{~mm}$. A sharp crack was introduced in the FE model and the crack blunting post precracking was neglected.

\section{Results and discussion}

\subsection{Williams' elastic field}

Three nominal load cases, $\Delta K=15,20$ and $25 \mathrm{MPa} \sqrt{m}$, were examined in the experiments, and the full-field deformation in the FOV was obtained in each case. An attempt was made, in the first instance, to correlate the DIC measurements with the numerical fitted results from the series expansion of Williams [24]. The stress intensity factor (SIF) K was obtained by fitting the displacement data obtained from the DIC to the Williams' series expansion using an algorithm DICITAC [14]. According to Williams, the displacement field ahead of a crack tip may be expressed as infinite series, which may be written as follows, omitting the terms of order $r^{3 / 2}$ and above:

$$
\begin{aligned}
& u=\frac{K_{I}}{2 \mu} \sqrt{\frac{r}{2 \pi}} \cos \frac{\theta}{2}\left(\kappa-1+2 \sin ^{2} \frac{\theta}{2}\right)+\frac{K_{I I}}{2 \mu} \sqrt{\frac{r}{2 \pi}} \sin \frac{\theta}{2}\left(\kappa+1+2 \cos ^{2} \frac{\theta}{2}\right)+\frac{T}{8 \mu} r(\kappa+1) \cos \theta \\
& v=\frac{K_{I}}{2 \mu} \sqrt{\frac{r}{2 \pi}} \sin \frac{\theta}{2}\left(\kappa+1-2 \sin ^{2} \frac{\theta}{2}\right)-\frac{K_{I I}}{2 \mu} \sqrt{\frac{r}{2 \pi}} \cos \frac{\theta}{2}\left(\kappa-1-2 \cos ^{2} \frac{\theta}{2}\right)+\frac{T}{8 \mu} r(\kappa-3) \sin \theta
\end{aligned}
$$


where $u$ and $v$ are displacements in $X$ and $Y$ directions, respectively. $K_{I}, K_{I I}$ and $T$ are SIF for mode I, mode II and T stress, respectively. $\mu$ is the shear modulus and $\kappa=$ $(3-v) /(1+v)$ for plane stress, $v$ is the Poisson's ratio; $r$ is the radial distance from crack tip and $\theta$ is the phase angle in a polar coordinate system with the crack tip at the centre. The displacement data from the DIC measurements were pre-processed to remove rigid body motions and then fitted to six terms of Williams series to obtain the values of $K_{I}$ as a function of applied load. The fitting strategies, including the appropriate field of view, the subset size and the size of the measurement window recommended in [15] were considered and adopted as appropriate. Specifically, a subset size of 49 pixels $\times 49$ pixel, and a step size of 6 pixels were used. About $1 / 3$ of the crack was inside of the area of interest.

Fig. 4 shows the displacement contours ahead of the crack-tip in the y-direction from the DIC measurements and the regressions from Williams' (left), and the stress intensity factor $\mathrm{K}$ against $\mathrm{P} / P_{\max }$ (right), where the $\mathrm{K}$ was determined by fitting the DIC displacement data to the Williams series ( 6 terms considered adequate [25]). An area about $800 \times 700 \mu \mathrm{m}^{2}$ was selected for the fitting, excluding the areas of poor correlation due to image noise. The precise sizes of images chosen for the fitting in the three load cases load cases varied slightly, due to the differences in the rigid body motions occurred.

It is clear that the displacement contours by the regression analysis (dashed contours) do not match those by the DIC displacement (solid contours) at all load cases considered. What is more, overestimations of $\mathrm{K}$ occurred at higher load levels for all cases also. In all cases, when $P / P_{\max } \leq 0.4-0.5$, the crack-tip deformation is still within SSY condition, so a good agreement between the analytical values and results from elastic regression may be achieved. When the load level increases, plastic component also increases hence when the total deformation, including the plastic component, was fitted into the regression, overestimations become unavoidable. These results show clearly that SIF $\mathrm{K}$ is inadequate for characterising the crack tip field in the cases studied, and a non-linear parameter is required.

\subsection{Estimation of crack tip plasticity}

Crack tip plasticity was estimated from the FE analysis and the results are shown in Fig. 5 and Fig. 6. The contours of normal stress $\sigma_{y y}$ ahead of the crack-tip at the maximum loading for $\Delta K=$ 15, 20 and $25 \mathrm{MPa} \sqrt{\mathrm{m}}$ are shown in Fig. 5, where the region marked by the red dash lines is the plastic zone (PZ) simulated by the FE method, and the region marked by black dash lines is the $P Z$ estimated by the Irwin's equation [26]:

$$
r_{p}=\frac{1}{2 \pi}\left(\frac{K_{\max }}{\sigma_{y s}}\right)^{2}
$$

where $\sigma_{y s}$ is the yielding stress and $K_{\max }$ is the maximum SIF applied. 
The boundaries of PZ calculated by both the FE elastic-plastic analysis and Eq. 8 are presented in Fig. 6 . The sizes of PZ estimated from the FE elastic-plastic analysis are generally smaller than those calculated by Eq. 8, which may be attributed to the modification from the prehistory of fatigue pre-cracking, when the crack tip region experienced forward and reversed deformation [27]. From Fig. 5, the plastic zone sizes are estimated to be $0.35,0.63$ and $1.1 \mathrm{~mm}$ from the crack tip, and the crack tip is located in the centre of a FOV $(1.2 \mathrm{~mm} \times 1.1 \mathrm{~mm})$, thus the plastic zone size is about $58 \%$ of the half-length of the FOV for $\Delta K=15 \mathrm{MPaVm}$, whilst filled the entire half-length of FOV for $\Delta K=20$ and $25 \mathrm{MPaVm}$, which further illustrates that the SIF method is invalid as a characterisation parameter.

Fig. 6 shows the distributions of the normal stress $\sigma_{y y}$ at the maximum loads for $\Delta K=$ 15,20 and $25 \mathrm{MPa} \sqrt{m}(\mathrm{R}=0.1)$ at five selected points ahead of the crack-tip, plotted as a function of the distance to the crack-tip from both the analytical solutions (9) and the FE simulations.

The analytical elastic solution for the normal stress $\sigma_{y y}$ is given by:

$$
\sigma_{y y}=\frac{K_{I}}{\sqrt{2 \pi r}} \cos \left(\frac{\theta}{2}\right)\left[1+\sin \left(\frac{\theta}{2}\right) \sin \left(\frac{3 \theta}{2}\right)\right]
$$

where $K_{I}$ is the applied SIF for Mode I, $\theta$ is the polar angle ( $\theta=0$ in this work) and $r$ is the radial coordinate $(r=0.3,0.6,0.9,1.2$ and $1.5 \mathrm{~mm})$. As expected, the values of $\sigma_{y y}$ from the elastic-plastic $\mathrm{FE}$ analysis deviate from the analytical elastic solution when the yield stress $\left(\sigma_{y}=280 \mathrm{MPa}\right)$ is exceeded. The attenuation effects of crack tip plasticity on the normal stress are evident close to the crack tip.

\subsection{COD vs $\mathrm{P} / \mathrm{P}_{\max }$}

The measured CODs are plotted as a function of normalised load for $\Delta K=15,20$ and $25 M P a \sqrt{m}$, and the results are presented in Fig. 7, together with those obtained from the FE analysis at the selected locations behind the crack tip (Fig. 2). A distinct "knee", or "crack opening", is identifiable in most cases, particularly away from the crack tip, although the instant when it occurred differs for different measurement locations and different load cases. The crack opening load $P_{\text {open }}$ was identified by one of the standard methods [28] from the compliance curves (Fig. 7). According to ASTME647 [29], the determination of opening force from compliance is based on the observation that when a cracked specimen is loaded up to the force at which the crack becomes fully open, the compliance (slope of the strain or displacement against force curve) attains a characteristic value and remains essentially constant upon further force increase. In our case, $P_{\text {open }}$ was obtained from the COD vs $\mathrm{P} / \mathrm{P}_{\max }$ plots using a linear regression fitted to the upper portion of the COD vs $\mathrm{P} / \mathrm{P}_{\max }$ curve in which $R^{2}$ is at its maximum value, then finding the intersection point with a regression line fitted to 
the lower portion of the COD vs $P / P_{\max }$ curve. The crack opening load thus obtained appears to vary with the measurement location, with similar behaviour observed close to the crack tip ( $1 \Delta$ and $2 \Delta$ ) or away from the crack tip (20 $\Delta$ and $29 \Delta)$ for all three load cases examined, a trend consistent with Carroll et al [11] and Tong et al [14]. Fig. 8 shows a summary of $P_{\text {open }} / P_{\max }$ as a function of the measurement locations to the crack tip for both DIC and FE results. It seems that $P_{\text {open }} / P_{\max }$ decreases with the increase of the distance to crack tip, also decrease with the increase of load level. Generally, $P_{\text {open }} / P_{\max }=0.68$ to 0.58 at $\Delta K=15 \mathrm{MPa} \sqrt{m}, P_{\text {open }} / P_{\max }=0.5$ to 0.42 at $\Delta K=$ $20 M P a \sqrt{m}$ and $P_{\text {open }} / P_{\max }=0.4$ to 0.34 at $\Delta K=25 M P a \sqrt{m}$. These values are broadly consistent with those reported previously under similar loading conditions [14], confirming that $P_{\text {open }} / P_{\max }$, although measurable from the compliant curves, is not a unique value from which the concept of crack closure is based.

\subsection{Crack driving force}

When significant plastic deformation beyond SSY occurs near a crack tip, stress intensity factor $K$ is no longer valid as a crack driving force (Fig. 4), and J-integral from an elastic-plastic analysis may be used. The J-integral introduced by Rice [1] is for the cases of traction-free on the crack surfaces and may lose the path-independency when plasticity-induced crack closure is present [30]. As plasticityinduced crack closure leads to compressive residual stresses in the plastic wake, the concept of residual stresses may be utilised to treat the cases of crack closure [31]. The effects of crack closure on J-integral may be considered by introducing the initial strains due to residual stresses into the Rice's J-integral equation [1] and the path-independent J-integral is then obtained [32,33]. The modified path-independent J-integral expression introducing initial strains $\varepsilon_{i j}^{0}$ in a $2 \mathrm{D} \mathrm{FE}$ model is expressed as [32]:

$$
J=\int_{A}\left[\left(\sigma_{i j} \frac{\partial u_{j}}{\partial x_{1}}-W \delta_{1 i}\right) \frac{\partial q}{\partial x_{i}}+\sigma_{i j} \frac{\partial \varepsilon_{i j}^{0}}{\partial x_{1}} q\right] d A
$$

where $A$ is the area enclosed by contour integration paths surrounding the crack tip; $W$ is the mechanical strain energy density, $u_{j}$ and $\sigma_{i j}$ are displacement and stress components in Cartesian coordinates, respectively; $x_{1}$ is the coordinate in the local crack driving direction, $q$ is a smooth function, $x_{j}$ is the nodal coordinates and $\varepsilon_{i j}^{0}$ is the initial strain. The introduction of residual stresses on J-integral calculation is available in the latest ABAQUS version [18]; the detailed procedures on introducing residual stresses due to fatigue pre-cracking in FE models are given in our previous work [33]. 
Following the elastic-plastic FE analysis using combined isotropic and kinematic hardening rules (Eqs.2,4) and the displacement data from the DIC, the values of total J-integral were calculated by using Eq. 10. The total J-integral consists of both elastic and plastic portions, as expressed [34]:

$$
J=J_{e}+J_{p}
$$

where the elastic $J_{e}$ was obtained by conducting a linear elastic FE analysis, whilst the plastic component $J_{p}$ was obtained by deduction of the elastic component $J_{e}$ from the total $J$ calculated from the integrated FE analysis. Fig. 9 show the total, the plastic and the elastic J-integrals against $\mathrm{P} / P_{\text {mas }}$. It appears that, in all cases, the elastic component is very small compared with the plastic component; and the values of J-integral increase significantly with the increase of load. Interestingly, however, there seems no distinct a "knee" in any of the cases examined, rather, the values of Jintegral increase continuously with the load in all cases. The results seem to suggest that, in the presence of large plasticity, the "crack closure" captured in the compliance curves does not appear to impact on the crack driving force represented J-integral for the cases studied. It should be noted that, although the DIC measurements cannot discriminate different physical mechanisms led to the "knee" registered on the compliance curves, plasticity-induced premature crack flank contact was observed in the present study in both the FE simulations and the visual observation, and is thought to be most likely responsible for the "knee". As the displacements measured by DIC were used as the boundary conditions in the integrated FE model, the lack of correlation with the calculated crack driving force expressed in J-integral seems to suggest that crack closure does not impact on the global crack driving force J-integral.

\section{Conclusions}

Full-field deformation near a fatigue crack tip has been captured using DIC and integrated FE in a stainless steel $316 \mathrm{~L}$ specimen under three selected load cases, $\Delta K=15,20$ and $25 M P a \sqrt{m}$. Attempts to map the deformation field using a William's series expansion proved to be unsuccessful due to the presence of significant plasticity beyond the SSY regime. The extent of crack tip plasticity was assessed using an elastic-plastic material model that considered both isotropic and kinematic hardenings. The crack opening displacements were tracked at selected locations to the crack tip for the three load cases studied, and the "opening load" was found to be dependent of the measurement location and the load level, not a unique value. The measured "opening load" does not appear to correlate with the crack driving force represented by the J-integral for all three cases examined. We therefore conclude that, for the cases studied here where significant plasticity exists at the crack tip hence plasticity-induced crack closure should prevail, there appears to be no impact of crack closure on the crack driving force. 


\section{References}

[1] J.R. Rice, A path-independent integral and the approximate analysis of strain concentration by notches and cracks, ASME J. Appl. Mech. 35 (1968) 376-386.

[2] D.S. Dugdale, Yielding in steel sheets containing slits, J. Mech. Phys. Solids, 8 (1960) 100-104.

[3] G.I. Barenblatt, The mathematical theory of equilibrium cracks in brittle fracture, Adv. In Appl. Mech. 7 (1962) 55-129.

[4] B.A. Bilby, A.H. Cottrell, K.H. Swindon, The spread of plastic yield from a notch, Proc. R. Soc. A, 272 (1963) 304-314.

[5] W. Prager, P.G. Hodge, Theory of perfectly plastic solids, Wiley, New York, USA, 1951.

[6] P.C. Paris, M.P. Gomez, W.P. Anderson, A rational analytic theory of fatigue, Trend. Eng. 13 (1961) 9-14.

[7] J.R. Rice, Mechanics of crack tip deformation and extension by fatigue. Fatigue Crack Propagation. 1967; ASTM STP 4:247-309.

[8] W. Elber, Ftigue crack closure under cyclic tension, Eng. Fract. Mech. 2 (1970) 37-45.

[9] J. Schijve, Fatigue crack closure: observations and technical significance, ASTM STP-982, (1988) $5-34$.

[10] W.T. Riddell, R.S. Piascik, M.A. Sutton, W. Zhao, S.R. McNeill, J.D. Helm, Determining fatigue crack opening loads from near-crack-tip displacement measurements, ASTM Special Technical Publication, (1999) 157-174.

[11] J. Carroll, C. Efstathiou, J. Lambros, H. Sehitoglu, B. Hauber, S. Spottswood, R. Chona, Investigation of fatigue crack closure using multiscale image correlation experiments, Eng. Fract. Mech. 76 (2009) 2384-2398.

[12] A.M. Korsunsky, X. Song, J. Belnoue, T. Jun, F. Hofmann, P.F.T De Matos, et al. Crack tip deformation fields and fatigue crack growth rates in Ti-6Al-4V, Int J Fatigue, 31 (2009) 1771-1779.

[13] F. Yusof, P. Lopez-Crespo, P.J. Withers, Effect of overload on crack closure in thick and thin specimens via digital image correlation, Int. J. Fatigue, 56 (2013) 17-24.

[14] J. Tong, S. Alshammrei, T. Wigger, C. Lupton, J.R. Yates, Full-field characterization of a fatigue crack: Crack closure revisited, Fatigue Fract. Eng. Mater. Struct. 41 (2018) 2130-2139.

[15] M. Mokhtarishirazabad, Evaluation of crack-tip fields from DIC data: A parametric study, Int. J. Fatigue 89 (2016) 11-19.

[16] J. Lemaitre, J.L. Chaboche, Mechanics of solid materials, Cambridge University Press, 1990.

[17] P. van Eeten, F. Nilsson, Constant and variable amplitude cyclic plasticity in 316L stainless steel, J. Test Eval. 34 (2006) 298-311. 
[18] ABAQUS 6.14, Hibbitt Karlsson and Sorensen Inc., Providence, RI, 2014.

[19] S.M. Barhli, M. Mostafavi, A.F. Cinar, D. Hollis, T.J. Marrow, J-integral calculation byfinite element processingof measured full-field surface displacements, Exp. Mech. 57 (2017) 997-1009.

[20] P.F.P. de Matos, D. Nowell, On the accurate assessment of crack opening and closing stresses in Plasticity-induced fatigue crack closure problems. Eng. Fract. Mech. 74 (2007) 1579-601.

[21] J.C. Newman Jr, H. Armen Jr, Elastic-plastic analysis of a propagating crack under cyclic loading. AIAA J. 13 (1975) 1017-23.

[22] K. Ogura, K. Ohji, FEM analysis of crack closure and delay effect in fatigue crack growth under variable amplitude loading. Eng. Fract. Mech. 9 (1977) 471-80.

[23] M. Nakagaki, S.N.Atluri, Fatigue crack closure and delay effects under mode I spectrum loading: an efficient elastic-plastic analysis procedure. Fatigue Fract. Eng. Mater. Struct. 1 (1979) 421-9.

[24] M.L. Williams, On the stress distribution at the base of a stationary crack, J. Appl. Mech. 24 (1957) 109-114.

[25] M. Zanganeh, Locating the Crack Tip Using Displacement Field Data: A Comparative Study, Strain 49 (2012) 102-115.

[26] G.R. Irwin, Analysis of stresses and strains near the end of a crack traversing a plate, J. Appl. Mech. 24 (1957) 361-364.

[27] R.C. McClung, Crack closure and plastic zone sizes in fatigue. Fatigue Fract. Eng. Mater. Struct. 14 (1991) 455-468.

[28] S. STOYCHEV and D. KUJAWSKI, Methods for crack opening load and crack tip shielding determination: a review. Fatigue Fract Engng Mater Struct 26 (2003) 1053-1067.

[29] ASTM E647: Standard test method for measurement of fatigue crack growth rates. Annual book of ASTM standards 3 (2011) 591-630.

[30] D.T. Ngoula, M. Madia, H.T. Beier, M. Vormwald, U. Zerbst, Cyclic J-integral: numerical and analytical investigations for surface cracks in weldments, Eng. Fract. Mech. 198 (2018) 24-44.

[31] R. Pippan, A. Honenwarter, Fatigue crack closure: a review of the physical phenomena. Fatigue Fract. Eng. Mater. Struct. 40 (2017) 471-495.

[32] Y. Lei, N.P. O'Dowd, G.A. Webster, Fracture mechanics analysis of a crack in a residual stress field. Int. J. Fract. 106 (2000) 195-216.

[33] B. Lin, C. Lupton, S. Spanrad, J. Schofield, J. Tong, Fatigue crack growth in laser-shock-peened Ti6Al-4V aerofoil specimens due to foreign object damage, Int. J. Fatigue, 59 (2014) 23-33.

[34] J.D.G. Sumpter, C.E. Turner, Method for laboratory determination of Jc, J.G. Kaufman (Ed.), Cracks and Fracture, ASTM STP 601, ASTM, Baltimore, MD (1976) 3-18. 


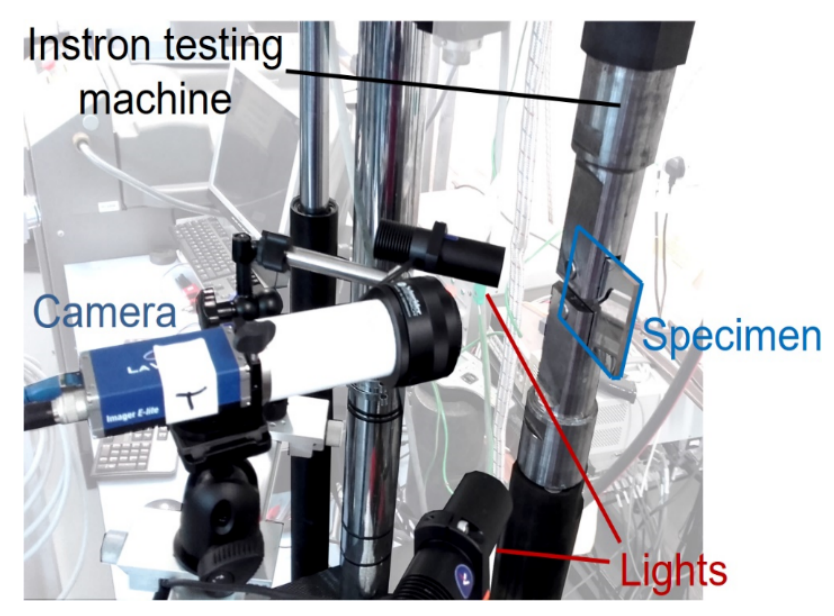

Fig. 1. The experimental setup for fatigue testing and DIC imaging.

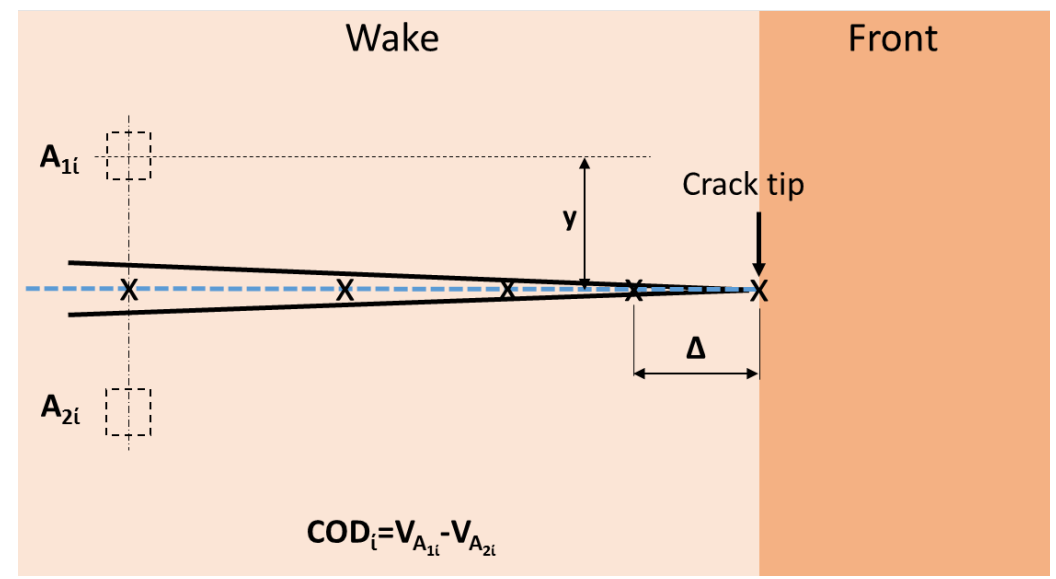

Fig. 2. An illustration of the tracking points used for recording the CODs in the crack wake. The CODs were calculated from the vertical displacements of $A 1 i$ and $A 2 i$ at a fixed distance to the crack plane $\mathrm{y}(30 \mu \mathrm{m})$; whilst the tracking points were chosen to be multiples of the average grain size $(\Delta=17 \mu \mathrm{m})$ $(\mathrm{j} \Delta, \mathrm{j}=1,2,20,29)$. 


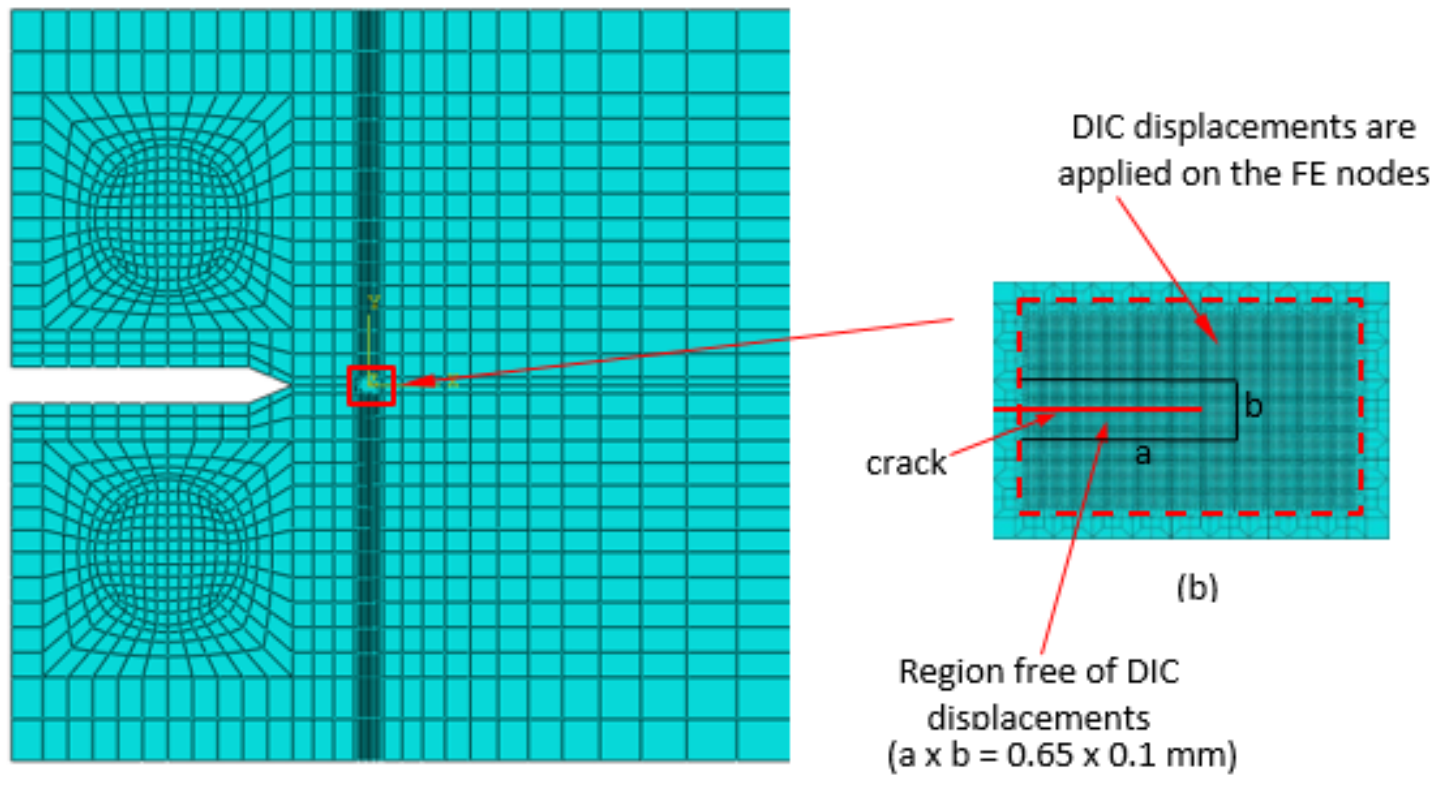

(a)

Fig. 3. (a) The finite element model of the CT specimen used for the analysis; and (b) the boundary conditions extracted from the displacements of FOV in the DIC analysis. 

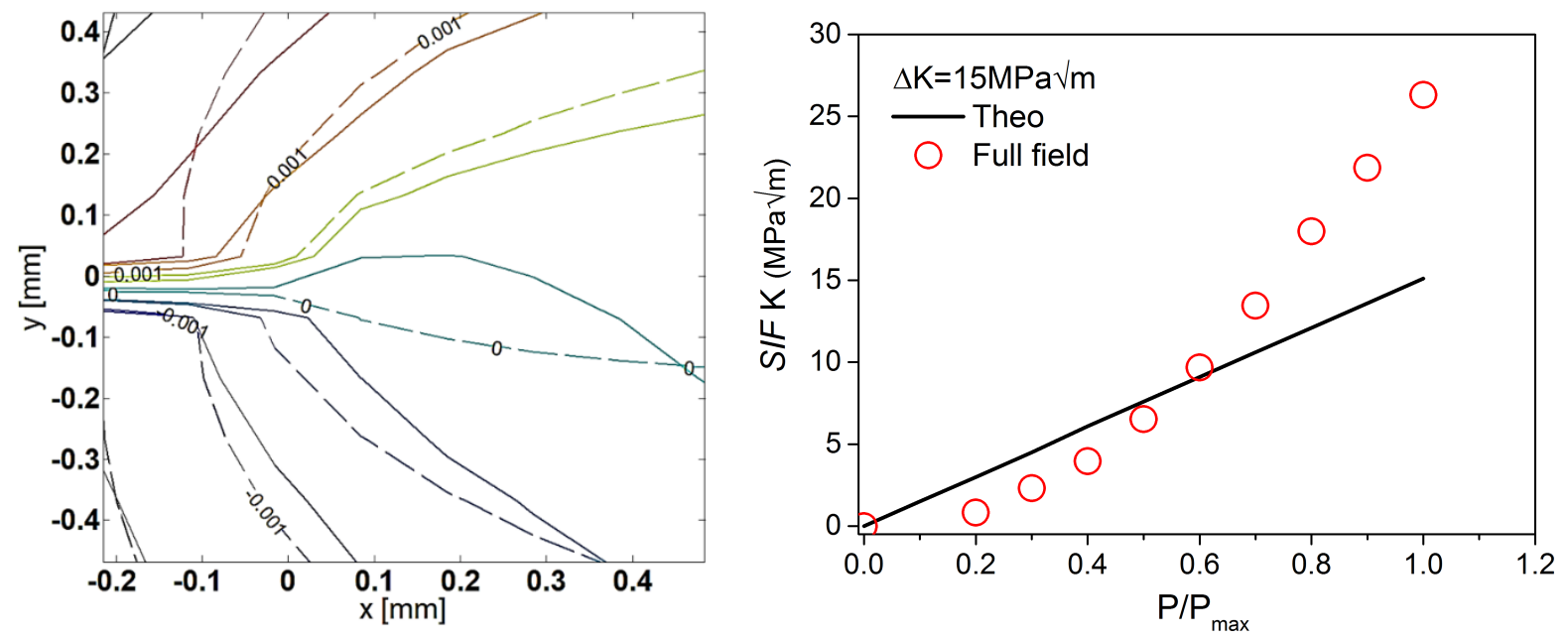

(a)
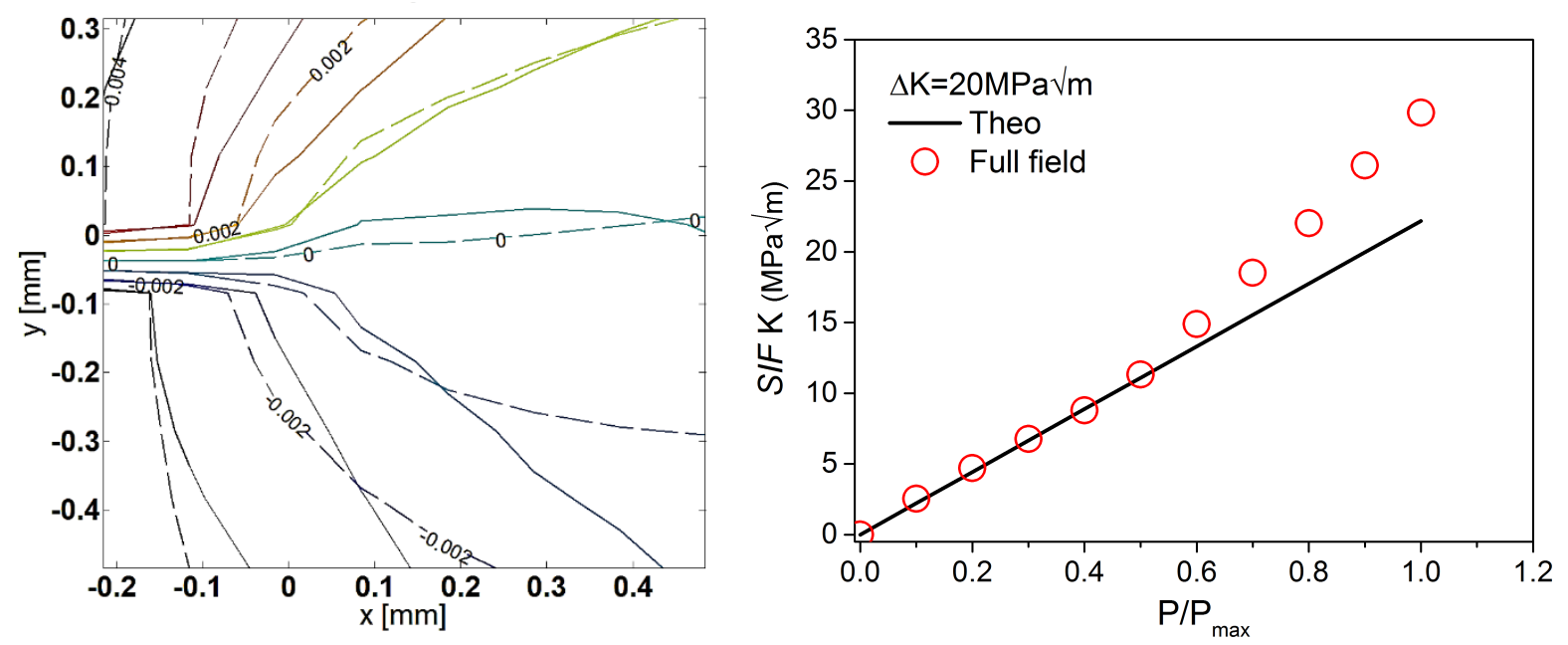

(b)
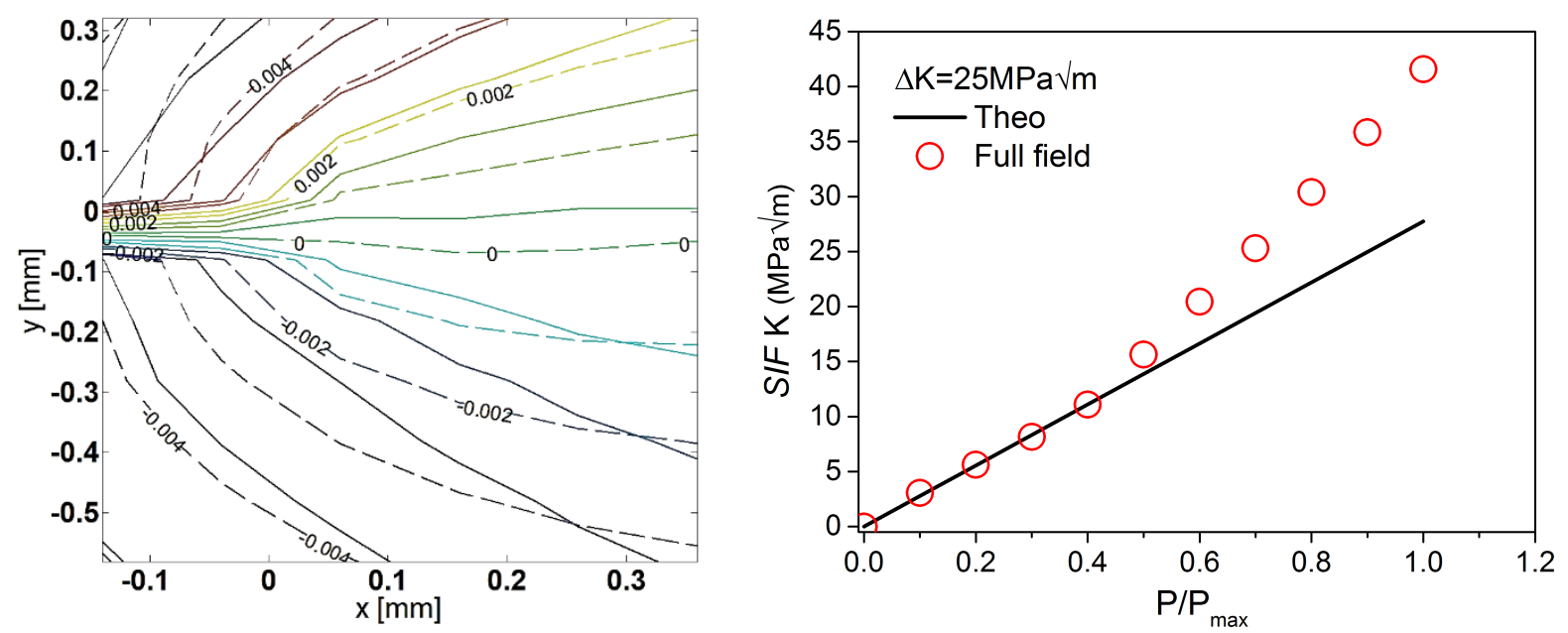

(c) 
Fig. 4. The displacement contours (left) measured from the DIC experiments and the linear regression (solid line: DIC; dashed line: Regression); and the analytical and the fitted values of $\mathrm{K}$ vs $\mathrm{P} / \mathrm{P}_{\max }$ (right) for the three load cases: (a) $\Delta K=15 M P a \sqrt{m}$; (b) $\Delta K=20 M P a \sqrt{m}$ and (c) $\Delta K=25 M P a \sqrt{m}$.

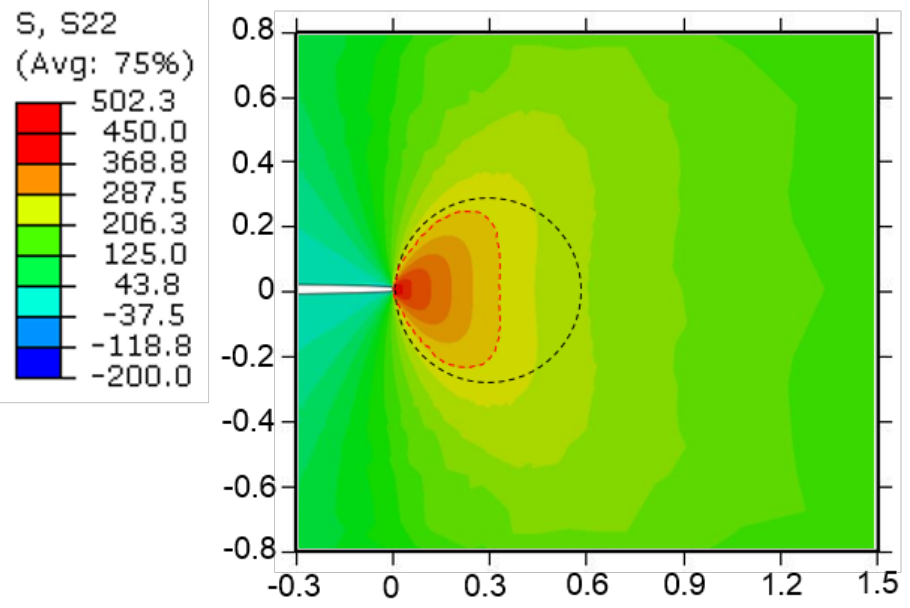

(a)

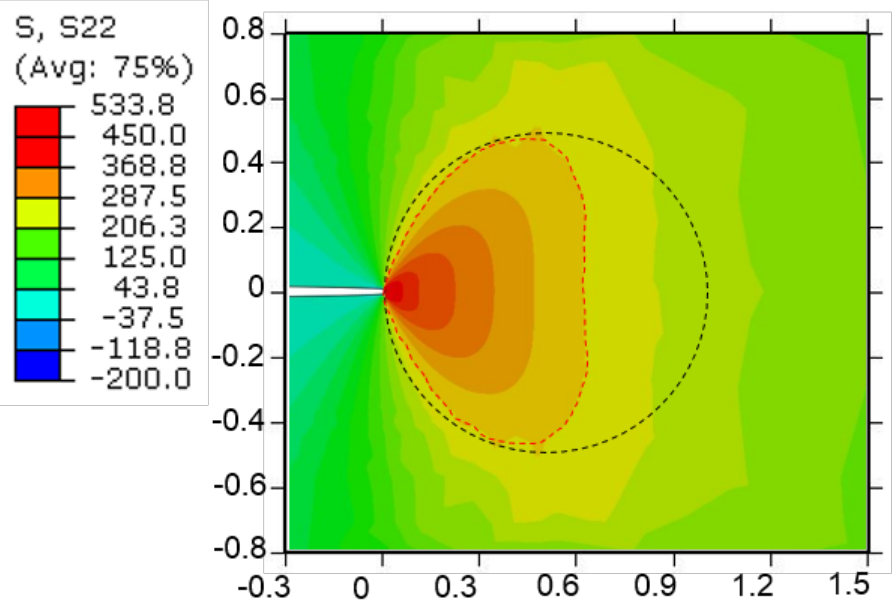

(b)

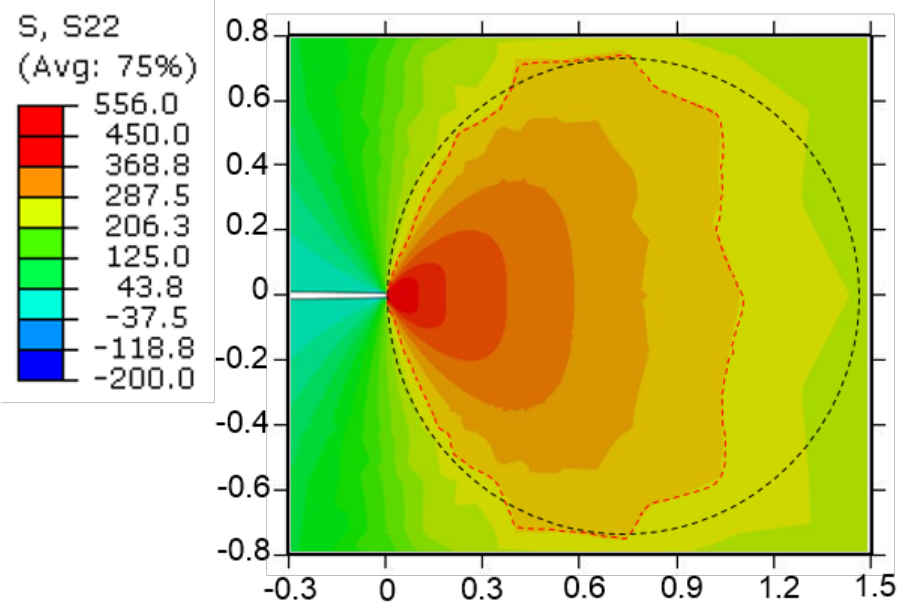


(c)

Fig. 5. The simulated plastic zones (marked red) and the estimated plastic zones of Irwin for the 3 load cases: (a) $\Delta K=15 \mathrm{MPa} \sqrt{m}$; (b) $\Delta K=20 \mathrm{MPa} \sqrt{m}$ and (c) $\Delta K=25 \mathrm{MPa} \sqrt{m}$.

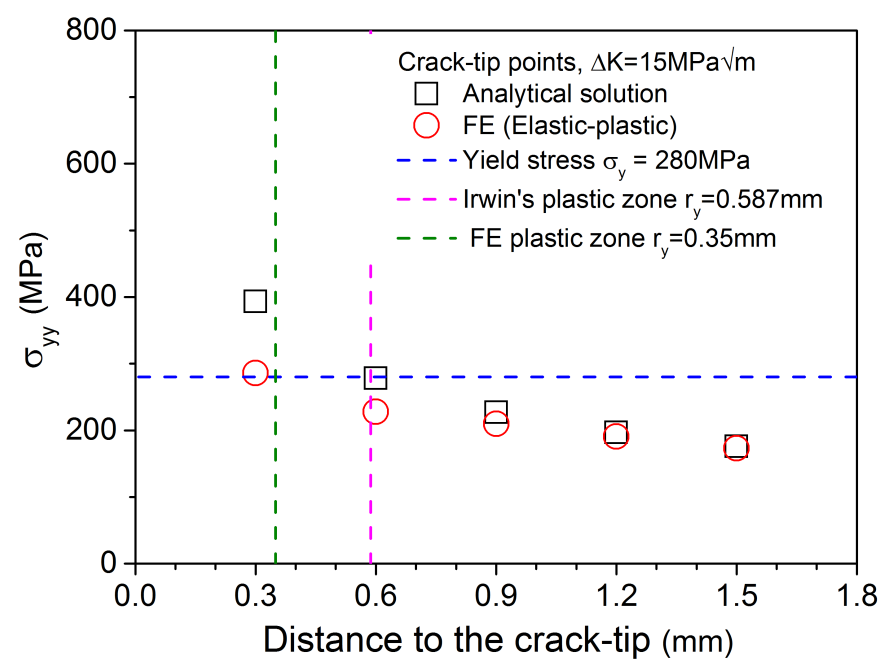

(a)

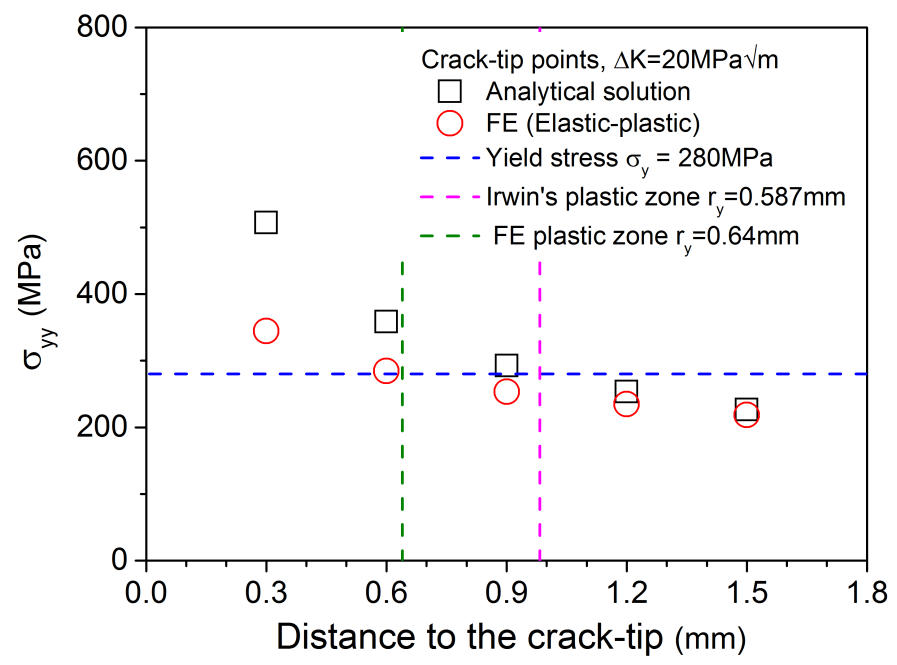

(b) 


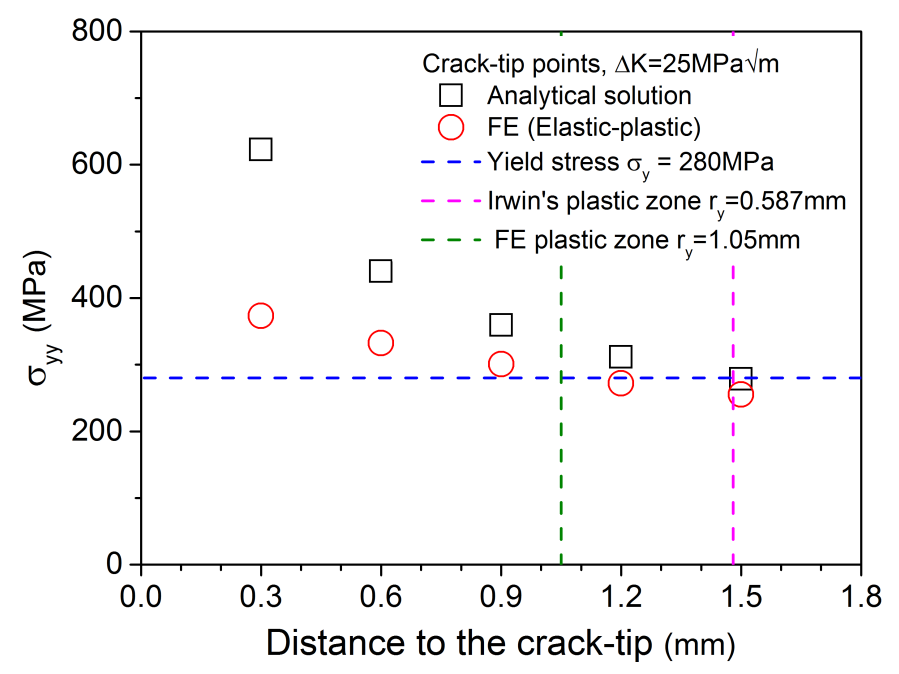

(c)

Fig. 6. The normal stress $\sigma_{y y}$ distributions obtained from the analytical (elastic) and the elasticplastic FE analysis as a function of the distance to the crack tip for the three load cases: (a) $\Delta K=$ $15 M P a \sqrt{m}$; (b) $\Delta K=20 M P a \sqrt{m}$ and (c) $\Delta K=25 M P a \sqrt{m}$.

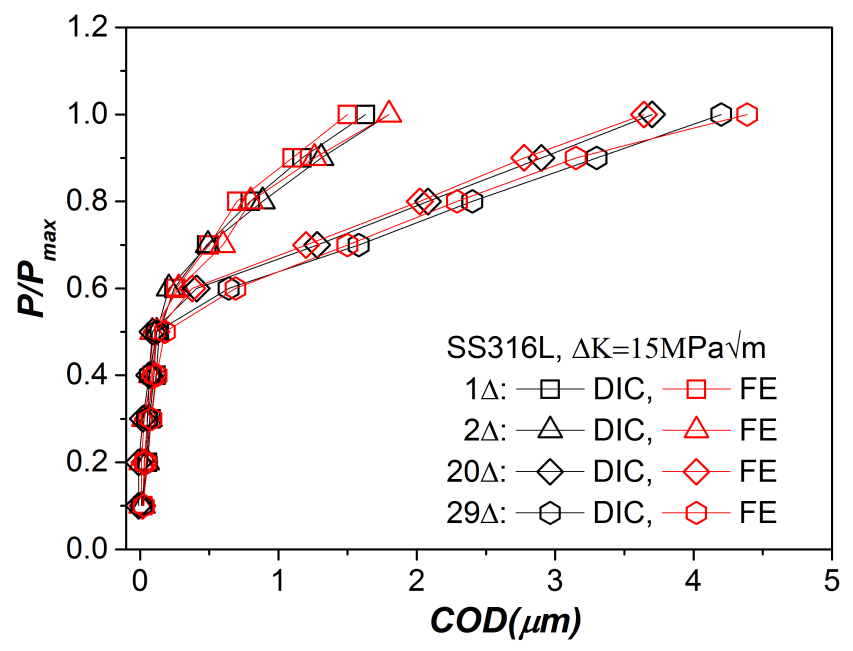

(a)

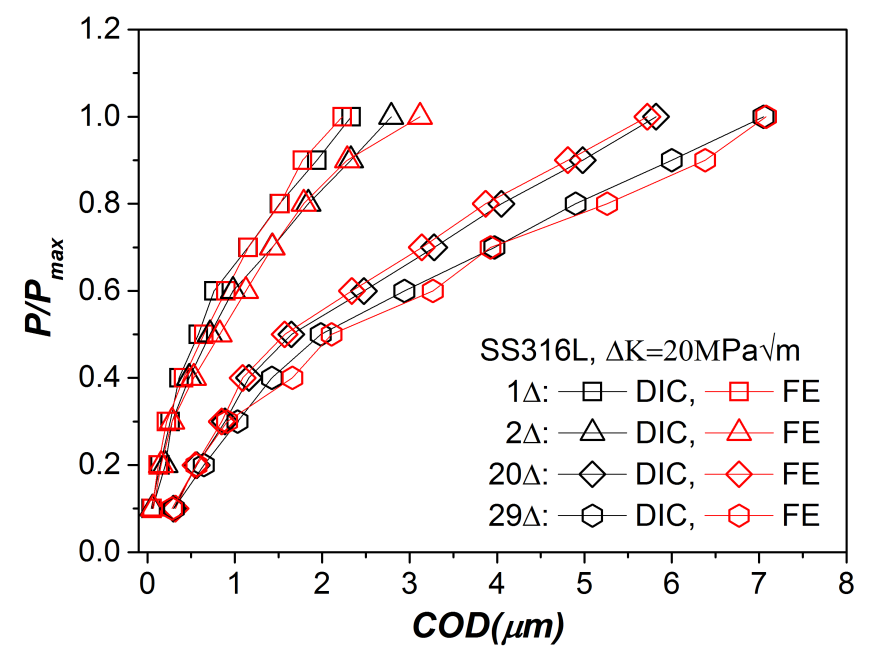


(b)

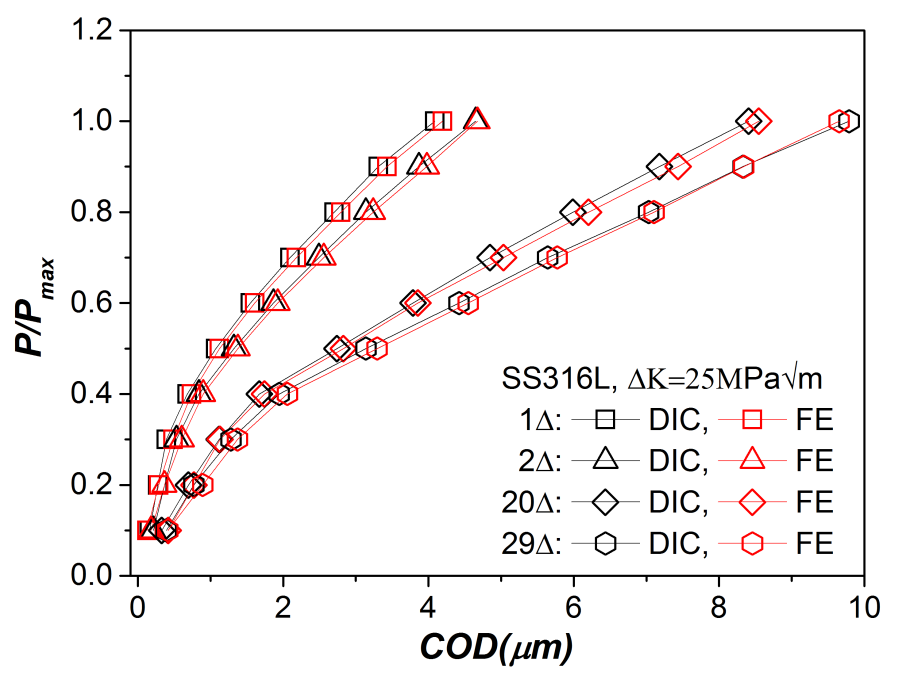

(c)

Fig. 7. Comparison of the experimentally measured (DIC) and FE simulated CODs at the selected locations along the crack flanks for the three load cases: (a) $\Delta K=15 M P a \sqrt{m}$; (b) $\Delta K=20 M P a \sqrt{m}$ and (c) $\Delta K=25 \mathrm{MPa} \sqrt{m}$.

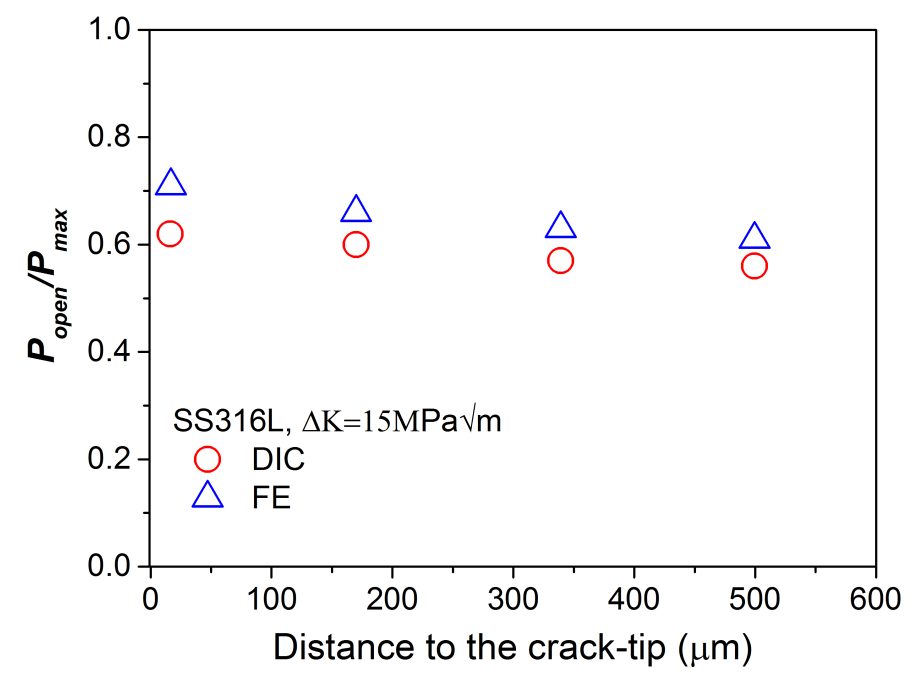

(a) 


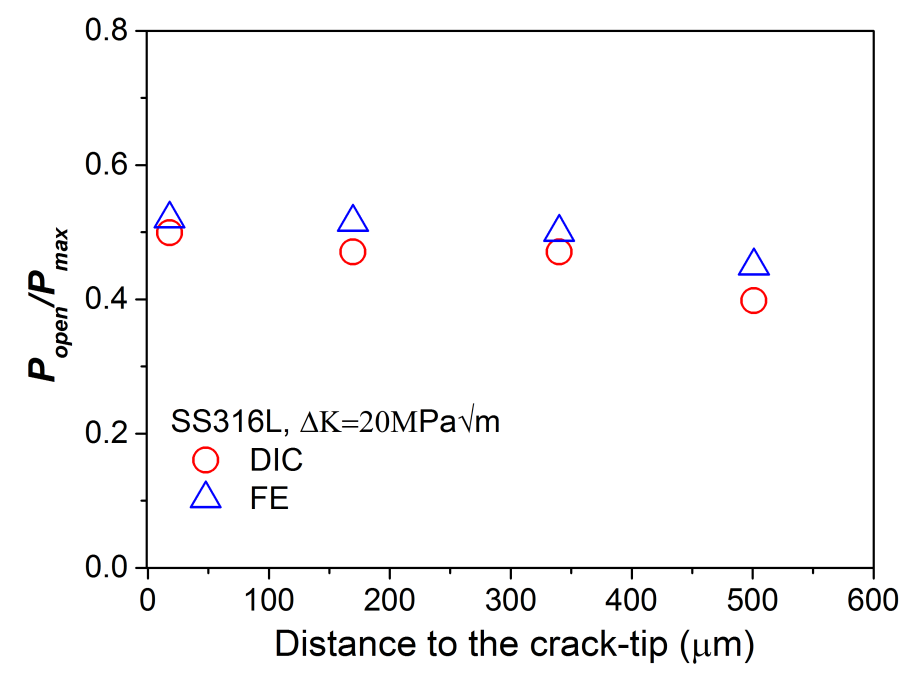

(b)

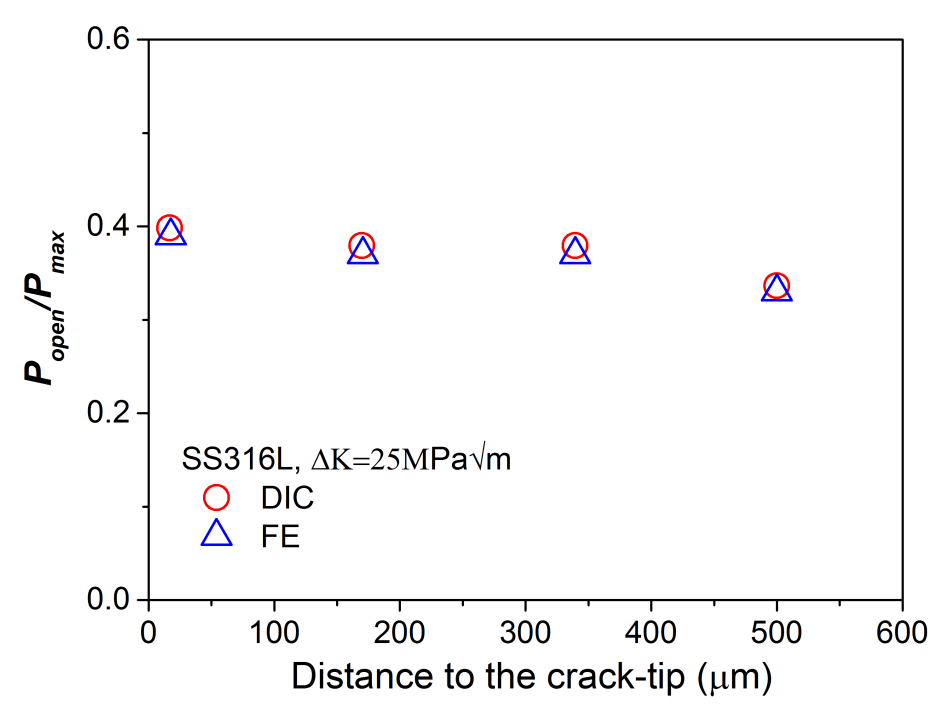

(c)

Fig. 8. Comparison of the crack opening loads form the DIC and the FE as a function of distance to the crack tip for the three load cases: (a) $\Delta K=15 \mathrm{MPa} \sqrt{m}$; (b) $\Delta K=20 \mathrm{MPa} \sqrt{m}$ and (c) $\Delta K=25 \mathrm{MPa} \sqrt{m}$.

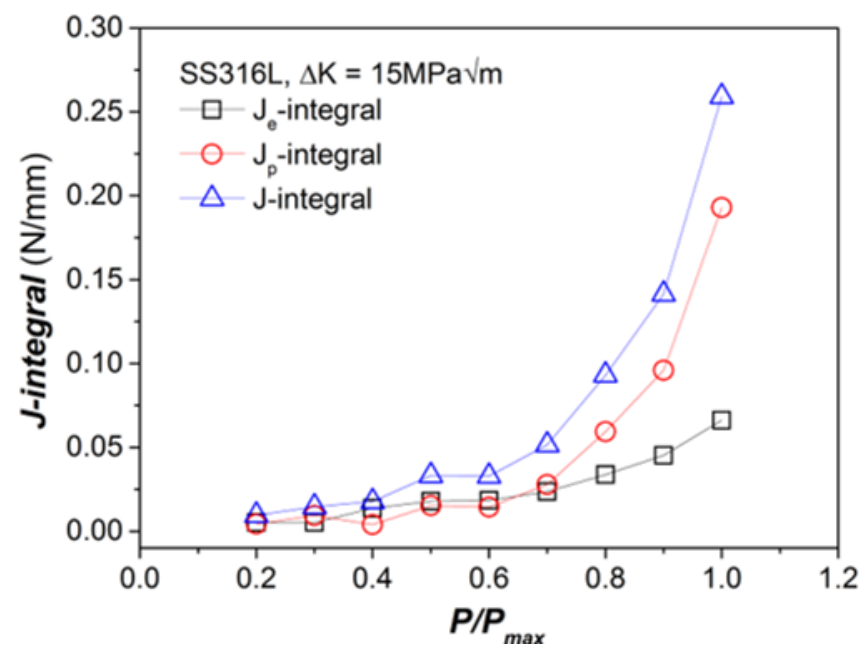


(a)

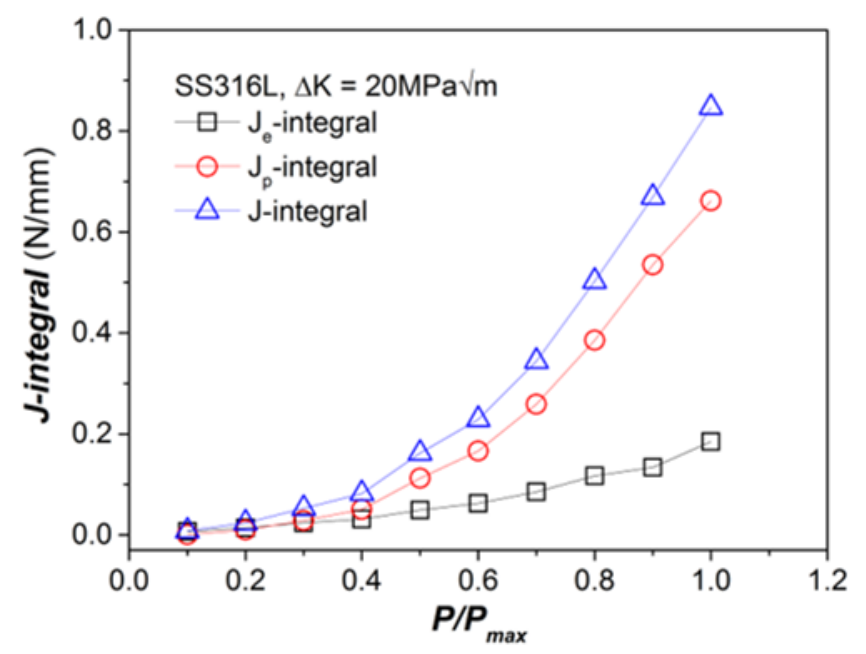

(b)

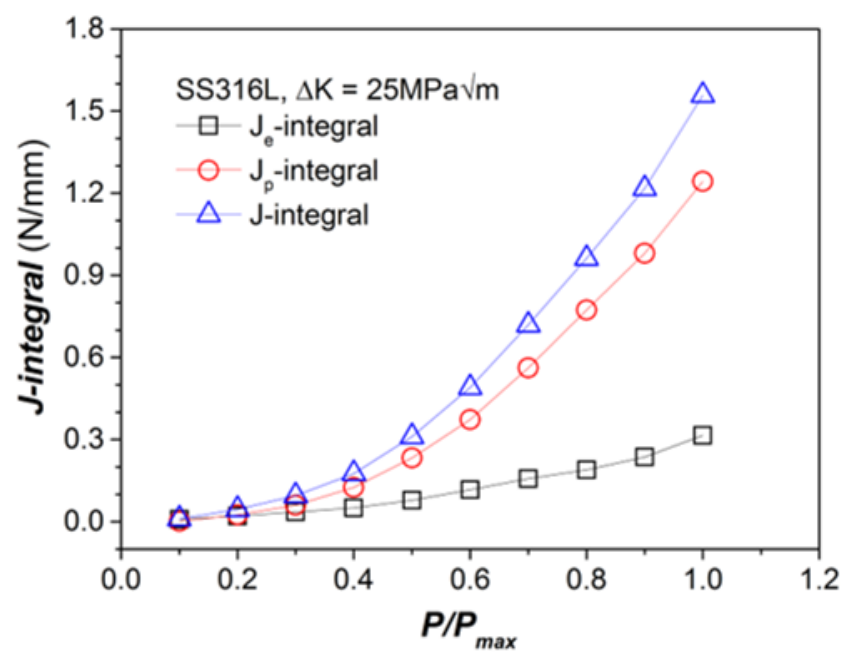

(c)

Fig. 9. The J-integrals obtained from the elastic and elastic-plastic FE analyses for the three load cases: (a) $\Delta K=15 \mathrm{MPa} \sqrt{\mathrm{m}}$; (b) $\Delta K=20 \mathrm{MPa} \sqrt{m}$ and (c) $\Delta K=25 \mathrm{MPa} \sqrt{m}$.

Table 1

The material parameters for SS316L used in the FE models

\begin{tabular}{cccccccc}
\hline$E(G P a)$ & $v$ & $\Delta \varepsilon(\%)$ & $\sigma_{0}(M P a)$ & \multicolumn{2}{c}{ Kinematic hardening } & \multicolumn{3}{c}{ Isotropic hardening } \\
\cline { 5 - 6 } & & & & $C(M P a)$ & $\gamma$ & $Q_{\infty}(M P a)$ & $\mathrm{b}$ \\
\hline 193 & 0.3 & 4.0 & 100 & 60000 & 280 & 200 & 6 \\
\hline
\end{tabular}

